\title{
Cinc experiències i reflexions metodològiques sobre PAprenentatge Basat en Projectes a les Ciències.
}

\author{
Martí Miró (mmiro234@xtec.cat) Grup de Treball EduWikiLab i Institut Marta Mata (Montornès del Vallès) \\ Anna Saperas (asaperas@xtec.cat) Grup de Treball EduWikiLab i Institut Duc de Montblanc (Rubí) \\ Mercè Tarragó (mtarrag7@xtec.cat) Grup de Treball EduWikiLab i Escola Sant Gervasi Cooperativa (Mollet \\ del Vallès) \\ Rosa Maria Tordera (rosamaria.tordera@epiagranollers.cat) Grup de Treball EduWikiLab i Escola Pia de \\ Granollers (Granollers) \\ Jordi Domènech-Casal (jdomen44@xtec.cat) Grup de Treball EduWikiLab, Institut Marta Estrada (Grano- \\ llers) i Departament de Didàctica de les Matemàtiques i les Ciències Experimentals, Universitat Autònoma \\ de Barcelona
}

L'Aprenentatge Basat en Projectes $(A B P)$ és un enfoc didàctic plural que respon a les necessitats educatives d'una educació científica més competencial i transferible. En aquest article es descriuen 5 activitats aplicades en matèries científiques en 5 instituts diferents, al voltant de la nutrició, l'energia, la contaminació, la taula periòdica i la connexió de models científics als contextos reals (publicitat, ciència en el dia a dia,...). Les experiències han estat desenvolupades i valorades en el marc del grup de Treball EduWikiLab. Es valora la seva aplicació en base a les observacions del professorat i una enquesta a l'alumnat $i$ es proposen orientacions per al desenvolupament d'activitats similars.

Paraules clau: Aprenentatge Basat en Projectes, Aprenentatge Basat en Productes, Interdisciplinarietat.

The Project-Based Learning (PBL) is a plural didactic approach in response to education needs which pursues a more competencial and transferible science education. In this article, we describe 5 activities which were applied in scientific subjects in 5 different highschools, about nutrition, energy, contamination, periodic table and the connection between scientific models and real contexts (advertisement, day-to-day science...). These experiences were developed and evaluated by the EduWikiLab work group. We evaluate the achievement of these activities based on the teacher's observations and a survey conducted to students and we propose some orientations for the development of similar activities.

Paraules clau: Project-Based Learning, Product-Based Learning, Interdisciplinarity

\section{INTRODUCCIó}

\section{L'ABP, una via de treball per a les Ciències.}

Diversos autors consideren que la preparació de l'alumnat per al segle XXI implica el desenvolupament d'habilitats complexes com el pensament crític, la col•laboració i comunicació, la creativitat i ca- pacitat d'establir connexions a nivells global i local, i l'ús de tecnologies per a l'aprenentatge (Ravitz, Hixson, English, i Mergendoller, 2012). En particular, a l'ensenyament de les Ciències a l'ESO, més que formar bons científics, es persegueix formar ciutadans competents científicament. La competència científica implica conèixer o reconèixer models científics, però també saber-los aplicar en la interpretació de contextos reals, i instrumentalitzarlos per a resoldre problemes. A més, requereix que 
l'alumnat adquireixi les habilitats i estratègies de construcció del coneixement, incloent les dinàmiques socials en què es produeix (Hodson, 1994, Pedrinacci, et al, 2012).

Aquestes habilitats, amb connexió profunda amb la dimensió científica de la competència ciutadana, són també presents en les matèries de ciències del currículum actual i, fins i tot, el currículum LOMCE espanyol actual (Ministerio de Educación, 2015), que en totes les matèries científiques inclou un bloc específic anomenat "Proyecto de Investigación”, format per els següents criteris d'avaluació:

1) Planear, aplicar, e integrar las destrezas y habilidades propias de trabajo científico.

2) Elaborar hipótesis, y contrastarlas a través de la experimentación o la observación y argumentación.

3) Discriminar y decidir sobre las fuentes de información y los métodos empleados para su obtención.

4) Participar, valorar y respetar el trabajo individual y en grupo.

5) Presentar y defender en público el proyecto de investigación realizado.

És evident que ni les habilitats complexes proposades per Ravitz et al (2012) ni la seva concreció curricular en les matèries de ciències poden aconseguir-se mitjançant metodologies transmissives, sinó que calen nous enfocaments metodològics en què l'alumnat participi activament, lideri, dissenyi i planifiqui. En aquest sentit, l'Aprenentatge Basat en Projectes (o $A B P$ ) suposa un espai metodològic candidat que permet el desenvolupament d'aquestes competències complexes (Grau, 2009, Trujillo, 2012).

\section{La diversitat didàctica de l'ABP.}

En l'ABP l'aprenentatge es produeix de forma contextualitzada mitjançant activitats significatives en les que l'alumnat s'autogestiona i aprèn instrumentalitzant els continguts amb un propòsit. Segons Kilpatrick (1918), en contrast amb la rutina reproductiva de les pràctiques transmissives, les experiències $A B P$ es caracteritzen per ser Actes amb propòsit (Purposeful Acts), i es podrien agrupar segons el seu propòsit en 4 tipus:

- Orientats a un Producte, on el propòsit és elaborar un producte o esdeveniment.

- Orientats a l'experiència estètica, on el propòsit és gaudir d'una peça musical, apreciar una pintura, etc.

- Orientats a resoldre un problema o pregunta (on podríem encabir la proposta de l'Ensenyament de les Ciències Basat en la Indagació -ECBI(Caamaño, 1992) com a metodologia activa pròpia de les ciències).

- Orientats a assolir una habilitat o coneixement específic, com aprendre a igualar reaccions químiques.

El paper del propòsit és diferent en els quatre tipus d'ABP de Kilpatrick: mentre en els tres primer tipus d'ABP, existeix i es comunica als alumnes un Propòsit (o Objectiu del Projecte, p.ex.: construir un vaixell) extern als objectius d'Aprenentatge que s'hi vinculen ( $p$. ex.: manipular la fusta, concepte de flotabilitat,...) en el darrer tipus no existeix un objectiu extern, sinó que s'opta per convertir l'aprenentatge en un projecte: "el projecte d'aprendre a", mancant de la dimensió contextualitzada i instrumental del coneixement.

Segons el grau d'obertura (la capacitat d'intervenció de l'alumnat en la definició dels objectius, la seqüència didàctica i la planificació), podríem treballar en projectes tancats (on tot el procés i producte és decidit per el professorat), projectes oberts (on els alumnes prenen totes les decisions), o projectes estructurats (on el professorat proposa uns objectius, guies, o bé materials generals i els alumnes poden decidir i planificar determinats aspectes). Als extrems d'aquesta gradació, trobem visions pedagògiques de l'ABP diferenciades, com a filosofia d'aprenentatge (en què l'aprenent i els seus interessos guien les experiències d'aprenentatge) o com a metodologia didàctica (en què el professor problematitza uns continguts predefinits en el marc d'un context rellevant) (Sanmartí, 2016, Domènech-Casal, 2016b).

\section{La complexitat de l'ABP a Secundària.}

La proposta de l'ABP coincideix en molts punts amb vies didàctiques recents d'innovació a les ciències i la tecnologia ben conegudes pel professorat, com el Tinkering, l'ECBI, STEM, (treball integrat de Ciència, Tecnologia, Enginyeria i Matemàtiques), Ciència Ciutadana, Recerca i Innovació Responsable, o Design Thinking i enfocs metodològics d'ampli espectre com la Flipped Classroom, l'Aprenentatge-Servei, les WebQuestes i la Gamificació (Chiva i Martí, 2016). Tot i això, si bé l'Aprenentatge Basat en Projectes és una proposta pedagògica d'una certa antiguitat (Kilpatrick, 1918), i compta amb una difusió força considerable en l'Educació Primària, a Secundària la seva aplicació és menys intensa. La major pressió curricular i la fragmentació del treball a l'aula en disciplines i especialistes que passen poques hores amb els seus alumnes fa complex el treball en ABP a Secundària 
(Lázpita, 2016, Domènech-Casal, en edició), ja que l'encaix de la interdisciplinarietat topa sovint amb estructures que requereixen solucions no només pedagògiques, sinó també tècniques (horaris, interdisciplinarietat, avaluació) que permetin la creació d'espais didàctics en què matèries i contextos, continguts i competències, es desenvolupin de manera concomitant (Del Moral, 2016).

Juntament amb aquestes dificultats relatives a la interdisciplinarietat, altres complexitats pròpies d'aquesta metodologia són l'encaix curricular, la definició d'Objectius del Projecte en contextos que incloguin de manera convincent i productiva elements del currículum (Des d'on comencem? Des dels continguts? Des del Context?), la significança i rellevància del context i les vies d'avaluació (Sanmartí, 2016, Trujillo, 2016).

\section{El nostre projecte de treballar per projectes.}

El grup de treball EduWikiLab [1] té per objectiu la innovació i pràctica en l'ensenyament de les ciències. Té una antiguitat de 5 cursos, al llarg dels quals ha dedicat esforços a diversos aspectes de l'ensenyament de les Ciències, com les pràctiques de laboratori (Besson et al, 2012), l'avaluació d'habilitats de raonament científic (Goytia et al 2015), l'oralitat a l'aula de ciències (Besson et al, 2015), i la lectura i el vídeo a les ciències. El curs 2015-2016 el grup ha estat format per 14 professors de ciències de diferents centres i s'ha proposat desenvolupar, aplicar i valorar experiències d'ABP a l'aula de ciències, amb l'objectiu de determinar l'efecte d'aquesta metodologia en la percepció dels alumnes sobre el seu propi aprenentatge i identificar claus metodològiques per a la creació de projectes a les Ciències. Per a fer-ho, hem fet diverses trobades en què hem descrit i comentat projectes d'altres professors, ens hem aconsellat els uns als altres en el desenvolupament dels projectes, que hem compartit en un espai Wiki [2] creat ad hoc i n'hem valorat conjuntament els resultats. Alhora, amb l'ajut d'una enquesta, hem demanat a 248 alumnes participants que expressin el seu acord/desacord amb diferents frases relatives als aprenentatges, la motivació i l'autonomia. Descrivim en aquest article els cinc dels projectes desenvolupats, en discutim els resultats juntament amb l'enquesta, i proposem orientacions a partir de les reflexions que n'han emergit.

\section{PROPOSTES DIDÀCTIQUES}

Com a eixos per al desenvolupament dels projectes, hem considerat que per mantenir la connexió al currículum ens era necessari fer projectes es- tructurats, amb diferents graus d'interdisciplinarietat, però sempre dins la consideració d'ABP com a metodologia didàctica, on el professor problematitza uns continguts, en un marc didàctic que s'ajustaria als següents eixos (Domènech-Casal, 2016b):

- Existeix un objectiu explícit extern i concomitant a l'aprenentatge (fer una exposició, construir un vaixell, dissenyar un envàs) vinculat a un producte o esdeveniment.

- L'objectiu extern inclou o parteix d'un conflicte que instrumentalitza el currículum i ubicat en un context real o versemblant.

- Els alumnes juguen un rol actiu en comunitat $i$ s'auto-gestionen.

\section{EI Joc de l'Energia, Escola Pia de Granollers.}

El projecte va consistir en construir un joc de taula on el fil conductor havia de ser l'Energia, les seves transformacions i la sostenibilitat o no sostenibilitat de la utilització d'algunes fonts d'energia. Es va portar a terme amb 120 alumnes de 2n d'ESO dins la matèria de Ciències Naturals. Al llarg de 7 sessions, els alumnes agrupats en equips de 4 persones van fer una pluja d'idees, van cercar informació sobre fonts d'energia i usos sostenibles, van crear el joc i les instruccions i van avaluar els productes resultants. Els materials i productes són disponibles en la web del projecte [3].

Als alumnes els va agradar la proposta i es van implicar molt en el disseny i construcció del joc, en el qual varen tenir total llibertat per crear. Van mostrar força autonomia en cercar la informació sobre els coneixements científics que els eren necessaris per dotar el joc de contingut. Hi va haver més dificultat a l'hora de fusionar la part més artística del joc amb els conceptes que havien d'estar implícits en el joc, ja que van dedicar més esforç a que el format del joc fos atractiu que no pas que contingués el màxim de coneixements que havien après en la recerca.

En finalitzar el projecte el vam avaluar amb una rúbrica que valorava l'originalitat de les normes i instruccions, l'acabat físic del tauler i la qualitat de la informació sobre l'energia inclosa en el joc. També vam crear una graella de co-avaluació pel seguiment diari dels grups, tot i que costava que els alumnes la portessin al dia. Les rúbriques usades són disponibles a la web de l'activitat [4]. L'experiència va serpositiva, ja que és una manera de treballar a classe en la qual els alumnes s'autoregulen i són més participatius en la cerca i 
adquisició del coneixement que necessiten per portar a terme el projecte.

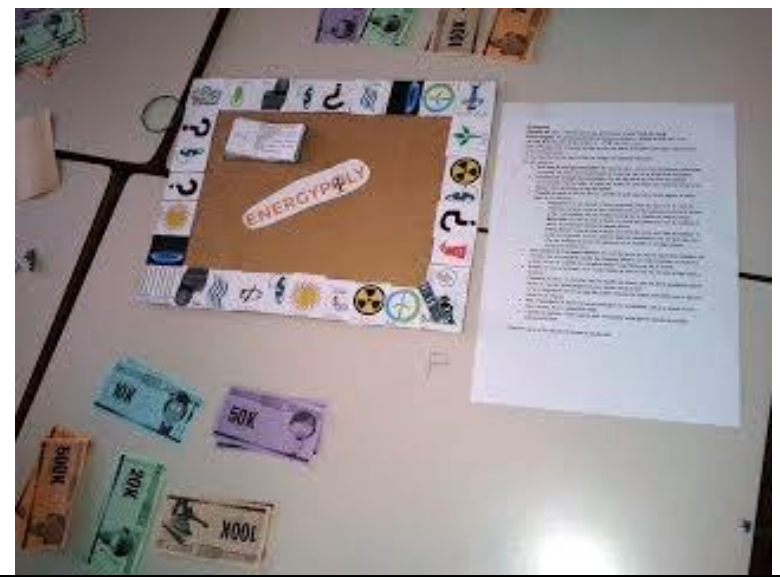

Figura 1: Imatge de l'Energypoly, un dels jocs creats pels alumnes.

\section{Mengem el què volem?, Institut Duc de Montblanc, Rubí.}

A 82 alumnes de ciències naturals de $3 r$ d'ESO se'ls va plantejar treballar l'aparell digestiu i la nutrició des de un punt de vista molt proper a la vida quotidiana: els anuncis audiovisuals de productes alimentaris. La publicitat és pràcticament inherent a les nostres vides, i els adolescents en són especialment sensibles. Diversos estudis (Campario et al, 2001, Moreno, 2006, Girón et al, 2015) revelen l'ús inadequat del lèxic o coneixement científic i la confusió interessada en l'ús de "l'autoritat científica". Amb l'objectiu d'aprendre sobre ciència i publicitat, juntament amb els docents del centre, Helena Cherta i Marc Llopis, es va proposar als alumnes el projecte "Mengem el què volem?' en què els alumnes havien de crear i exposar en un format de la seva elecció, per equips, un article exposant les seves conclusions respecte un anunci publicitari d'un producte alimentari.

Cada grup va escollir un anunci d'un producte alimentari i el va estar analitzant durant totes les sessions per poder treure'n conclusions sobre la credibilitat del missatge. Es van plantejar varies sessions per estudiar, per una banda, la comprensió de l'anunci (missatge, imatges, relació amb la ciència) recolzant-se $\mathrm{i}$ adaptant l'estructura del "Qüestionari CRITIC" (Prat et al.2008); i, per l'altre, qüestions científiques conceptuals sobre els aliments, nutrients, el seu pas per l'aparell digestiu, alguna relació amb el sistema endocrí i se'ls va animar a que dissenyessin un experiment propi. Finalment, havien d'argumentar si el missatge de l'anunci era creïble o no, tant per mitjà d'un text com oralment per a tota la classe, utilitzant tots els recursos i lèxic que havien estat treballant en totes les tasques prèvies.

Les sessions van ser pautades: cada sessió es va composar d'una tasca que s'havia de resoldre individualment, molt centrada en l'adquisició dels conceptes i una altra en grup, més centrada en l'aplicació dels coneixements a l'anàlisi del seu anunci. Els alumnes es van co-avaluar cada dia en el seu treball individual $i$ en grup, i la professora també els va avaluar, segons la metodologia d'avaluació dialògica integrada [5]. L'article i exposició final va ser també co-avaluada pels companys i avaluada per la professora.

Pel que fa a la valoració del projecte, els alumnes van valorar positivament el fet d'estudiar una qüestió quotidiana, i que els va resultar útil. Aquest fet, juntament amb què ells van triar l'anunci que volien estudiar va fer que es motivessin per voler resoldre el problema que se'ls plantejava. En general, els grups van treballar de forma autònoma i es van ajudar entre ells, encara que hi va haver alumnes que es van implicar poc, el que relacionem $a m b$ què alguns alumnes no fossin massa conscients de quins coneixements científics s'estaven tractant. Alguns alumnes van estar desconcertats per la proposta. En alguns casos, una sistematització dels conceptes hagués ajudat a recuperar la implicació d'alguns alumnes, ja fos com a explicació, construcció d'un mapa conceptual o, fins i tot, preparar un examen.

\section{La Taula PeriòBRICKa Institut Marta Mata, Montornès del Vallès.}

A la matèria de Ciències de la Naturalesa de $3 r$ ESO, després de treballar de manera teòrica conceptes com la teoria atòmica, els models atòmics i les característiques dels àtoms, es va proposar als 79 alumnes del curs elaborar una Taula Periòdica física en 3 dimensions construïda per ells mateixos, incloent les dades més importants de cadascun dels elements així com aplicacions, objectes quotidians i altres aspectes relacionats amb cada element. L'alumnat es distribuí en grups de 4 persones i es va assignar per atzar un element a cada alumne/a (4 elements per grup).

Cadascun dels elements es va treballar a partir d'un envàs tipus Tetrabrick, d'unes mesures determinades, que actuaria com a capsa, on hi inclourien la "informació científica" del seu element a la tapa: per fora, el nom (en diversos idiomes), símbol, massa, nombre atòmic i configuració electrònica simplificada i, per dins, l'etimologia, descobridor, any del descobriment $\mathrm{i}$ isòtops. Aquesta capsa, dissenyada i decorada segons el criteri de l'alumne, 
podia contenir dins seu objectes o materials que incloguessin l'element; només es demanà que el color exterior de la capsa fos d'un determinat color (segons l'element fos metall, semimetall, no-metall o gas noble, seguint el conveni de la Taula Periòdica del llibre de text utilitzat per l'alumnat)

Dins de la capsa de cada element, un cop feta la recerca de les dades, es podien incloure fitxes de colors de 3 categories, relacionades amb l'element en qüestió:

1) Fitxes de Cultura: amb cançons, pel•lícules, Ilibres o altres expressions artístiques o culturals que incloguessin l'element, indicant títol, intèrpret o autor o director i any de publicació i opcionalment, una còpia de la lletra o fragment on sortís l'element.

2) Fitxes de Societat: amb etiquetes d'aliments, medicaments, productes de neteja i altres substàncies habituals a les llars, que incloguessin el nom del producte i una etiqueta del mateix on es vegi clarament el nom de l'element, ja sigui formant un compost o en estat pur.

3) Fitxes de Tecnologia: amb objectes físics fets totalment o parcial amb l'element en qüestió i amb dades sobre el nom de l'objecte, les seves aplicacions i, opcionalment, el seu preu de compra.

La proposta d'aquest projecte es va presentar a l'Equip Docent i es va decidir dedicar la última setmana de curs a treballar en el Projecte des de totes les matèries, mantenint els horaris i realitzant activitats diferents: disseny de la capsa, i.e. mides, materials, distribució...(Visual i Plàstica); encaix i decoració de poliedres duals, associats als 4 elements de la primera Taula Periòdica; i.e. foc, aigua, aire, terra (Matemàtiques); elaboració d'un pòster d'un element per grup responent a les preguntes "Per què el nostre element és el millor?" i "Té un costat fosc el nostre element?' (Ciències Socials); traducció d'algunes de les fitxes i elaboració de paraules i frases amb els símbols dels elements de la Taula Periòdica (Llengües Anglesa i Francesa); elaboració d'un "Kahoot" de preguntes i respostes sobre els elements. (Llengües Catalana i Castellana); realització d'una gimcana per l'Institut amb l'objectiu de trobar codis QR amb accés a informació multimèdia sobre els elements i la Taula Periòdica (Educació Física); elaboració d'un memory amb peces de fusta amb el símbol i el nom dels elements (Tecnologia).

Com a via per a gamificar l'activitat per tal de donar una mica de motivació a l'alumnat, es va decidir fer una graella en la que s'anaven actualitzant cada 2 dies les puntuacions de les activitats que anaven realitzant, per part del professorat de cada matèria. Al final es va regalar una Taula Periòdica als membres de l'Equip que va obtenir més punts a la graella gamificada.

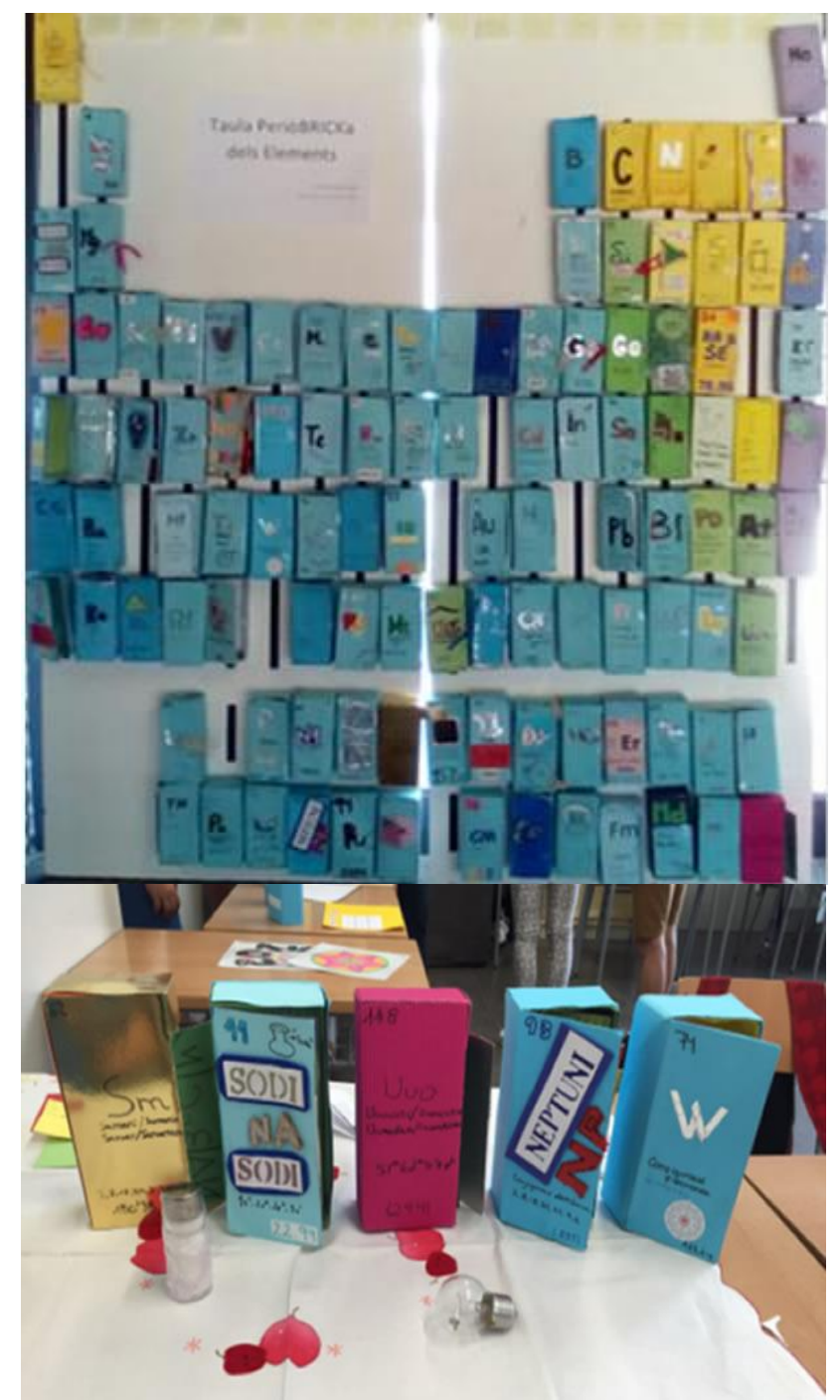

Figura 2. Exemples de produccions dels alumnes.

Per acabar, cada grup va muntar una paradeta amb tot el material elaborat i ho va presentar. Els grups que feien d'oients valoraven d'1 a 10 la informació rebuda i omplien una graella d'avaluació. Tot això va quedar reflectit a la nota final de la matèria, en un sentit o un altre, segons els criteris preestablerts per cada docent abans de començar el Projecte i explicats a l'alumnat.

La valoració general va ser bona, el Projecte va motivar a alguns alumnes que no havien mostrat interès durant el curs a treballar i col-laborar i ha generat una dinàmica de col•laboració entre el professorat molt fructífera. Es va compartir la incertesa 
de desenvolupar un projecte col-laboratiu, fent-losen partícips als alumnes, cosa que ha afavorit la seva implicació. Tot i així, alguns alumnes haurien necessitat un ajut en la planificació del temps, donada la quantitat i diversitat de productes

\section{La ciència en el dia a dia Escola Sant Gervasi Cooperativa, Mollet del Vallès.}

La ciència en el dia a dia és un treball per projectes que es va aplicar, per primera vegada, amb alumnes de 4t d'ESO -modalitat científica- de l'Escola Sant Gervasi, de Mollet del Vallès, durant el curs 2015-16. El projecte es va plantejar experimentar, demostrar i explicar, amb metodologia científica, accions o fenòmens de la vida quotidiana, amb l'objectiu de constatar que la ciència és del tot present en el nostre dia a dia.

El projecte es va estructurar en 9 sessions d'1 hora setmanal: 1 hora per a la tria del projecte, 1 per a analitzar què sabien i què volien saber, 3 per a la recerca d'informació i el desenvolupament teòric, 2 pel desenvolupament pràctic 0 experimental i 2 per a l'avaluació final. L'alumnat es va autoorganitzar en grups de 2 a 4 persones i va decidir el públic objectiu a qui aniria adreçada la recerca (alumnat, famílies o professorat). Per a cadascuna de les sessions, l'alumnat va deixar constància documental dels aspectes organitzatius: especificació de la sessió -tasques i el seu repartiment-; resultats aconseguits; i avaluació, tant a nivell individual com de grup de treball, amb l'ajut de bastides proposades per altres autors [6]. En les primeres sessions, l'aplicació d'aquesta metodologia, va posar de manifest que l'alumnat estava molt més habituat a organitzar-se de manera oral i informal que no pas per escrit i de manera sistemàtica. Fins i tot va ser freqüents les opinions que consideraven que la sistematització per escrit era una pèrdua de temps. Pel que fa a les avaluacions, van ser necessàries diverses sessions fins arribar a un grau de crítica i sinceritat amb ells mateixos i la resta de companys.

Va caldre temps per triar les accions o fenòmens a experimentar, ja que l'alumnat no relacionava la ciència amb el dia a dia i tendia a reproduir experiències ja realitzades anteriorment al laboratori. Per aquest motiu, va ser necessari orientar a l'alumnat amb preguntes sobre accions quotidianes, del tipus: Com...? Per què...?

Després de superar les dificultats inicials, pensar i replantejar les temàtiques, i matisar molts aspectes; els projectes triats van permetre experimentar amb accions de la vida diària alhora que van esdevenir un recordatori de continguts científics treballats en cursos anteriors. Alguns exemples va ser: una maqueta explicativa de l'aparell digestiu; un vídeo de simulació al laboratori del procés de la digestió (Figura 3a); la presentació de l'aigua com a dissolvent universal de diferents substàncies; les pàgines web amb els efectes del tabac en l'aparell respiratori o l'efecte d'un àcid en el carbonat de calci; els vídeos que donen resposta científica a diverses situacions, com ara la sensació de mareig al llevar-nos de cop, la dissolució del cacau amb llet (Figura 3b), la suor, les ferides, els polls, la tos, l'orina, les dents, els somnis o l'expansió dels badalls.

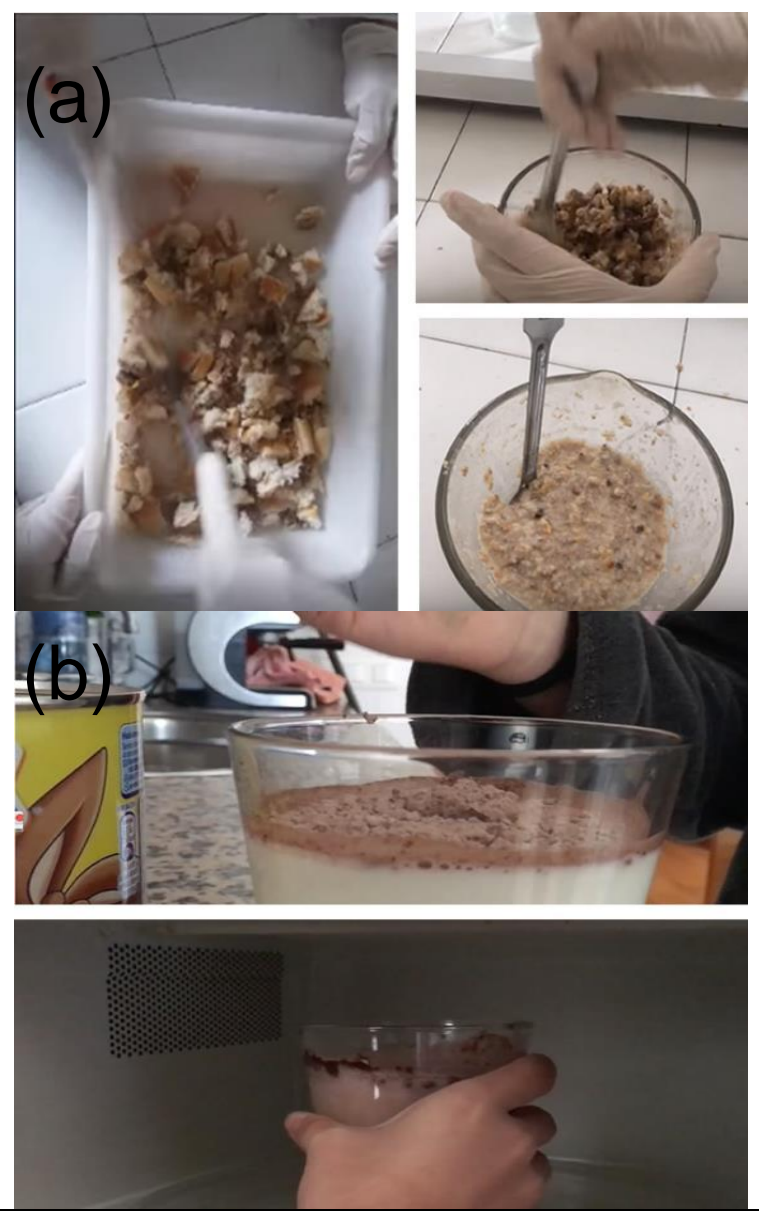

Figura 3. Imatges dels vídeos fets per l'alumnat en què (a) es simula el procés de la digestió i (b) s'explica la dissolució del cacau amb llet

\section{Congrés Cientific Escolar Institut Marta Estrada, Granollers.}

Es va proposar als 58 alumnes de $1 \mathrm{r}$ d'ESO de I'Institut Marta Estrada de Granollers organitzar i participar com a investigadors en un Congrés Científic Escolar sobre contaminació en capes fluides de la Terra (Atmosfera i Hidrosfera). El projecte educatiu de l'Institut incloïa el treball per projectes com a eix definitori, i els alumnes participants ja 
havien desenvolupat altres activitats de treball per projectes anteriorment (Domènech et al, 2016, Ruiz i Domènech-Casal, en edició). El projecte es va proposar conjuntament per tot l'equip docent com a projecte interdisciplinar de final de trimestre, de manera que s'hi va participar des de diverses matèries, en dos nivell didàctics al que van participar tots els alumnes:

Equips de recerca (estructurat, vinculat als continguts científics): Els alumnes, organitzats en equips de tres alumnes, van planificar i dur a terme una recerca científica i la van comunicar en format de pòster científic. Es van proposar diverses tècniques analítiques (detecció química de contaminants específics per colorimetria, anàlisi biològic de mostres), de diferents composts i paràmetres (fosfats, carbonats, nitrats, ozó, sulfats, temperatura...). Se'ls va convidar a formular preguntes del tipus " $H i$ ha variacions del contaminant $X$ al llarg del curs del riu?" "I segons el dia de la setmana?", i a dissenyar una recerca per a respondre-hi. Aquesta part del projecte es va dur a terme des de les hores de Ciències Naturals (12 hores lectives), incloent també explicacions teòriques sobre cicle de l'aigua, contaminació, canvi climàtic, etc. Els alumnes van usar diverses plantilles de suport del Projecte C3 (Domènech-Casal, 2016a) per al disseny d'experiments i l'elaboració del pòster científic. Per a l'elaboració del pòster, es van fer aportacions des d'altres matèries: per aprendre a fer histogrames amb les dades en full de càlcul (Matemàtiques) i revisar les tipologies textuals i la correcció lingüística dels pòsters (Llengua). Abans d'imprimir-los per al congrés, cada equip va presentar al seu grupclasse el seu pòster, que va ser objecte de coavaluació amb l'ajut d'una rúbrica d'avaluació de pòsters científics [7]

Comissions d'organització (obert, vinculat a les competències i l'autonomia): Es va explicar als alumnes el funcionament d'un congrés científic i es va elaborar juntament amb ells un llistat de les tasques que calia per a organitzar-lo i cada alumne es va unir a una comissió formada per a cada tasca (àrea gràfica, espais i horaris, logística, relacions públiques, presentadors i seguretat, patrocini i coffe-break, etc.). Els alumnes van disposar d'una hora cada dues setmanes al llarg del trimestre, en què cada professor acompanyava 2-3 comissions en la seva tasca auto-gestionada d'organitzar el congrés.

Els alumnes van quedar molt satisfets del congrés (on van assistir científics reals) i dels procediments científics i de comunicació i organització que havien desenvolupat, i, en especial, del fet de ser ells mateixos els qui ho van organitzar. Pensem que hauria calgut més esforços perquè els alumnes connectessin les conclusions de la seva recerca als models científics treballats (cicle de l'aigua, cicles biogeoquímics del carboni, fòsfor, etc.). Els materials del projecte resultant, "1st Earth Fluids Scientific Congress" són disponibles a la pàgina web creada ad hoc [8].

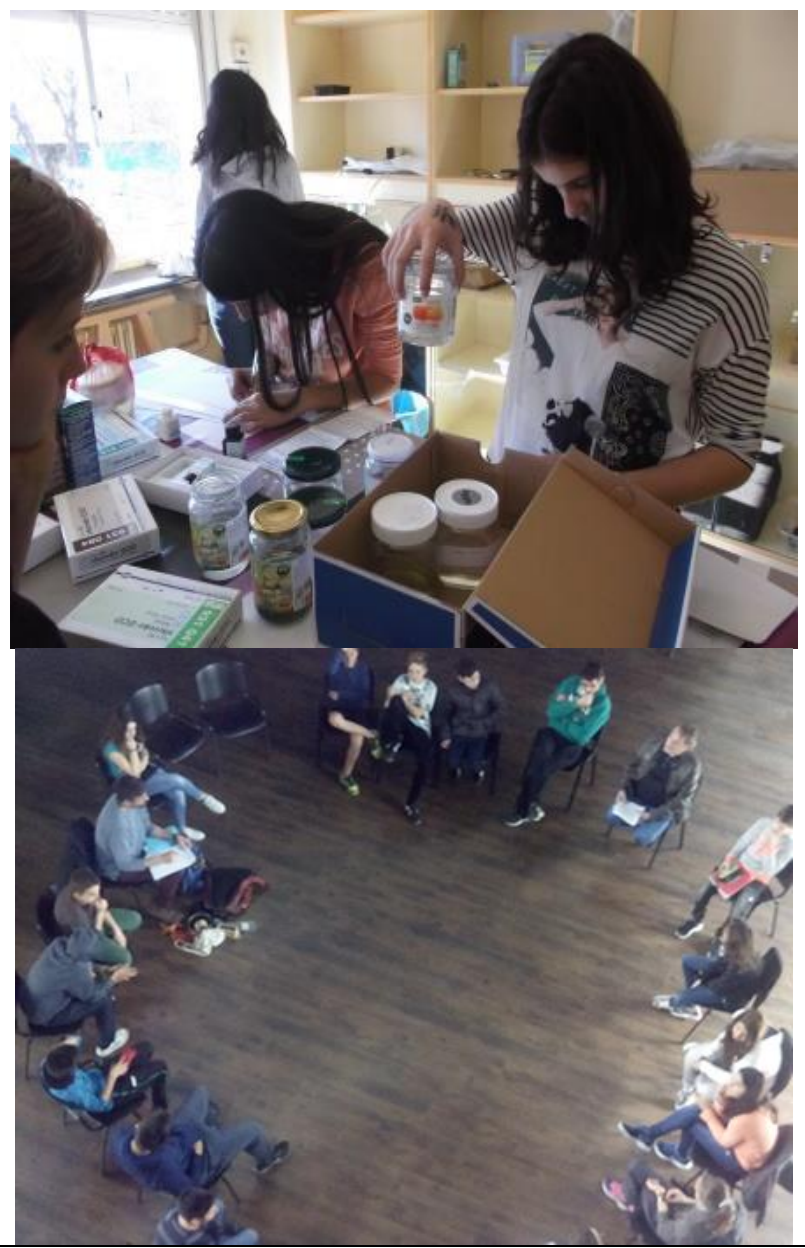

Figura 4. La participació de tots els alumnes en els dos nivells didàctics (equips de recerca i comissions d'organització) va permetre mantenir un equilibri entre continguts i competències

\section{RESULTATS}

Els projectes creats ofereixen diferents graus d'obertura i interdisciplinarietat i tenen connexions amb metodologies com les WebQuestes, la Gamificació i la ECBI. De manera general, en tots els projectes el punt de partida per al disseny ha estat l'elecció d'un tema o model científic (taula periòdica, energia, nutrició, contaminació,...) o l'habilitat de connectar models científics als contextos reals (publicitat, ciència en el dia a dia,...), per a posteriorment establir un producte a elaborar per els alumnes, més o menys contextualitzat. 
Els diferents projectes han proposat reptes conceptuals (Què és sostenible? Què és alimentació equilibrada?), procedimentals (dissenyar un experiment, anàlisi crítica de la informació) i epistèmics (diferenciar publicitat de ciència, participar en esdeveniments científics) propis de les ciències i útils per al desenvolupament de la competència científica.

En general, els professors hem usat instruments (rúbriques, productes parcials o finals) per a avaluar el projecte i acompanyar l'alumnat en el seu procés, si bé apreciem que, mentre els "Objectius del Projecte" són evidents en el seu acompanyament i avaluació, ha estat complex avaluar i acompanyar els "Objectius d'aprenentatge" i, en alguns casos, no hem trobat maneres de saber de manera clara si els alumnes havien assolit a nivell individual els continguts o habilitats científiques que pensem que la matèria aporta al projecte. De manera general, la participació de l'alumnat en la planificació del projecte ha resultat molt beneficiosa per a la seva implicació. La gestió de l'aula ha resultat complexa, en ocasions per alumnes desconcertats que no tenien clar què s'esperava d'ells. En algun projecte la interdisciplinarietat s'ha originat de forma espontània, el que considerem una via natural per a la implantació del treball per projectes als centres educatius.

En l'enquesta realitzada, pel que fa als aprenentatges, els 248 alumnes participants a l'enquesta consideren que han après conceptes $(72 \%)$ i procediments $(60 \%)$ de ciències, a treballar en equip (74\%) i espavilar-se $(81 \%)$. En comparació a les classes normals, els alumnes pensen que treballant per projectes aprenen més (68\%) i coses més útils (67\%) que en classes normals. Un $68 \%$ considera que podria aplicar el que ha après.

Pel que fa a la motivació, consideren que s'ho passen millor $(87 \%)$, voldrien fer projectes més sovint $(76 \%)$, i estan satisfets del resultat (77\%) o fins $i$ tot que si no els haguessin posat nota també haurien volgut fer el projecte (60\%). Alguns alumnes han parlat de motu proprio del projecte amb algú de fora de l'institut $(47 \%)$ o n'han compartit idees o fotografies en xarxes socials (17\%).

En relació a l'autonomia, alguns alumnes consideren important triar el tema projecte $(75 \%)$ o com planificar-lo $(78 \%)$ i prefereixen que no els orientin gaire $(43 \%)$. Un $28 \%$ pensa que amb aquest enfocament treballen menys i un $32 \%$ afirma preferir seguir el llibre de text o digital.

Als alumnes els han estat d'ajut les orientacions del/la professor/a $(62,5 \%)$, els materials proporcionats $(64 \%)$ i els companys (56\%).
Mentre en les preguntes relatives a la motivació, les diferències entre projectes són gairebé inexistents, en les preguntes relatives a l'aprenentatge i l'autonomia hi ha variacions importants entre projectes. En els comentaris lliures dels alumnes hi ha mencions abundants relatives a la dificultat de treballar en grup i a la inquietud de disposar d'un espai (apunts, classe magistral, etc.) on condensar un corpus teòric.

\section{CONCLUSIONS}

Pel que fa al disseny, pensem que, més que estructurar de manera molt tancada el projecte, és útil partir d'un tema molt vinculat al currículum, emmarcar-lo en un context o conflicte rellevant i definir de manera molt clara la pregunta/repte inicial de forma motivadora, promovent que els alumnes participin a planificar (fins i tot a nivell de calendari) el desenvolupament del projecte. La tasca de comentar inicialment projectes d'altres autors i discutir entre els membres del grup de treball els projectes en construcció ha estat molt útil. Pensem que en l'aplicació dels projectes, cal comunicar als alumnes els objectius d'aprenentatge i les raons pedagògiques que ens porten a treballar per projectes, perquè altrament alguns alumnes tenen la sensació de no estar aprenent en el sentit convencional del terme. Alguns dels aprenentatges resultants del treball per projectes (creativitat, disseny d'experiments, iniciativa, comunicació en formats científics, treball en equip) es visualitzen poc i s'explicita poc la seva relació amb el currículum, i això fa que alumnes i famílies puguin tenir una visió esbiaixada de la utilitat de la metodologia. Incloure esdeveniments finals de comunicació i presentació a un públic extern o, fins i tot, intern és una manera de donar força al projecte que es pot articular a nivell de centre (Álvarez et al, 2016).

Pel que fa als objectius d'aprenentatge, pensem que la convivència d'Objectius del Projecte i Objectius d'Aprenentatge és complexa, i correm el risc de perdre de vista els Objectius d'Aprenentatge propis de la matèria. En ocasions, el conflicte a resoldre pot tenir el pes massa desplaçat a "Com expliquem això que resolem?" enlloc de "Com resolem això usant continguts científics?". En particular, són necessàries eines d'avaluació que permetin avaluar de manera més clara si els objectius d'aprenentatge s'han assolit a nivell individual, potser usant instruments com l'observació a l'aula o els diaris d'aprenentatge. Pensem que és important trobar maneres d'ubicar el conflicte en el centre de contextos científics, i evitar que els continguts científics es converteixin en un paisatge passiu en el que es desenvolupen exclusivament altres habilitats desvinculades de la ciència. Determinar clara- 
ment quins són els objectius competencials d'aprenentatge de les ciències, en les seves dimensions conceptual, procedimental o epistèmica (Llorente et al, en avaluació), i les eines per a avaluar-los amb anterioritat al projecte ens servirà també per a detectar possibilitats didàctiques en el projecte. Incloure en l'activitat moments o de síntesi o modelització explícita que vinculin el projecte a models científics pot ser de molta utilitat, tal com proposen altres autors per a metodologies actives com l'ECBI (Simarro, Couso i Pintó, 2013).

La interdisciplinarietat és complexa, no només per raons d'horaris, sinó perquè implica també la col•laboració entre docents que possiblement tenen visions diferents sobre l'ensenyamentaprenentatge, l'avaluació, l'atenció a la diversitat,... Pensem, però, que no només és una via per a afavorir que els continguts es treballin de manera més contextualitzada (i, per tant, més competencial) sinó també de formació entre iguals i creació d'una cultura de centre.

Determinats enfocaments polítics i legislatius (com les revàlides) són una amenaça per a metodologies com el treball per projectes, perquè prioritzen habilitats de baix nivell cognitiu, com la memorització o aplicació acrítica. Els materials d'aquests i altres projectes desenvolupats durant el curs 2015-2016 en el marc del treball d'innovació i pràctica del grup de treball EduWikiLab són disponibles al Wiki EduWikiLabABP [2] i el blog del grup de treball [1]. Durant el curs 2016-2017, el grup de treball continuarà treballant en l'ús d'ABP per a l'ensenyament de les Ciències. El treball desenvolupat per EduWikiLab es suma als esforços d'altres agents i iniciatives col•laboratives d'abast divers en el treball per projectes, com la Xarxa de Competències Bàsiques [9], la Xarxa d'Instituts Innovadors de l'ICE-UAB [10], i la Xarxa d'Instituts Instituts Projectant [11].

\section{AGRAIIMENTS}

Els projectes i reflexions inclosos en aquest article formen part de la tasca d'innovació i pràctica educativa en l'ensenyament de les ciències desenvolupada el curs 2015-2016 en el grup de treball EduWikiLab sobre el treball per projectes. Els autors agraïm al Centre de Recursos del Professorat de Granollers i al professorat i alumnat dels instituts participants la seva col-laboració i recolzament. Reflexions incloses en aquest article s'emmarquen en la recerca metodològica duta a terme al grup de recerca consolidat LICEC (referència 2014SGR1492) per AGAUR i finançat per el Ministerio de Economía y Competitividad (referència EDU2015-66643C2-1-P).

\section{REFERÈNCIES}

ÁLVAREZ, J.A., DOMÈNECH-CASAL, J., GARROTE, A., GASCO, J., OLIVEROS, C., RODRÍGUEZ, L. (2016). Investiguem i ens comuniquem científicament: una proposta de centre com a dinamització de la Competència Científica. Revista Ciències, 31, 12-20.

BESSON, I., GOYTIA, E., MIRÓ, M., DOMĖNECHCASAL, J. (2015). Pràctiques mudes, congressos científics, seminaris de recerca $i$ altres dinàmiques científiques d'oralitat al laboratori i a l'aula. Revista Ciències, 29, 15-24.

BESSON, I., DOMĖNECH-CASAL, J., GOYTIA, E., SÁNCHEZ, N. (2012). EduWikiLab: la creació d'un espai col॰laboratiu sobre treballs pràctics al laboratori i al taller. Revista Ciències, 23, 15-20.

CAMPANARIO, J., OTERO, J., MOYA, A. (2001). Invocaciones y usos inadecuados de la ciencia en la publicidad. Enseñanza de las Ciencias. 19(1), 45-56.

CHIVA, O., MARTÍ, M. (2016). Métodos pedagògicos activos y globalitzadores. Conceptualización y propuestas de aplicación. Barcelona, Graó.

DEL MORAL, S. (2016, en edició). Del conocimiento al aprendizaje, un camino sin retorno. Materias y competencias en el ABP. Cuadernos de Pedagogía, (en publicació, novembre 2016).

DOMÈNECH, X., LLORENTE, I., RUIZ, N., SERRA, C., ULLDEMOLINS, M., ARRIZABALAGA, A., DOMĖNECH-CASAL, J. (2016). XYZ-Stars $i$ Solar System Pathway: una experiència museística de treball per projectes sobre les constel-lacions $i$ el Sistema Solar. Revista Ciències 31, 21-28.

DOMĖNECH-CASAL, J. (2016a). Proyecto C3: indagación científica, lengua y contextos en la ESO. Aula de Secundaria, 19, 15-19.

DOMĖNECH-CASAL, J. (2016b). Apuntes topográficos para el viaje hacia el \#ABP. Cuadernos de Pedagogía, 742, 59-62.

DOMÈNECH-CASAL, J. (en edició). Proyectando BioGeo, un itinerario de trabajo por proyectos contextualizados basado en la indagación y la Naturaleza de la Ciencia. Alambique, Didáctica de las Ciencias Experimentales. 
GIRÓN, J.R., BLANCO, À; LUPIÓN, T. (2015) Uso de la publicidad de un producto alimenticio para aprender un modelo sobre las defensas en el intestino humano. Un estudio en $3^{\circ}$ de ESO. Revista Eureka sobre Enseñanza y Divulgación de las Ciencias, 12 (2), 278-293.

GOYTIA, E., BESSON, I., GASCO, J., DOMÈNECH-CASAL, J. (2015). Evaluar habilidades científicas. Indagación en los exámenes. ¿Una vía para cambiar la práctica didáctica en el aula? Alambique, Didáctica de las Ciencias Experimentales, 79.

GRAU, R. (2009). Altres formes de fer ciència. Alternatives a l'aula de secundària. Rosa Sensat, Barcelona.

KILPATRICK, W.E. (1918). The Project Method: the use of the purposeful act in the educative process. Teachers college, Columbia University.

LÁZPITA, A. (2016, en edició). ¿Solo en la bolera? El Aprendizaje Basado en Proyectos desde una assignatura. Cuadernos de Pedagogía (en publicació, novembre 2016).

LLORENTE, I., DOMĖNECH, X., RUIZ, N., SELGA, I., SERRA, C., DOMĖNECH-CASAL, J. (en avaluació) Un Congreso Científico en secundaria: articulando el Aprendizaje Basado en Proyectos y la indagación científica. Investigación en la escuela, enviat.

MAJÓ, F., BAQUERÓ, M. (2014). 8 ideas clave. Los Proyectos Interdisciplinarios. Graó, Barcelona.

MANS, C. (2004). El residu: la Taula periòdica dels aliments. Revista de la Societat Catalana de Química, 5, 82-85.

Ministerio de Educación, Cultura y Deporte (2015). Currículum de Biología y Geología, 4ํㅡㄹ Real Decreto 1105/2014, de 26 de diciembre, por el que se establece el currículo básico de la Educación Secundaria Obligatoria y del $\mathrm{Ba}-$ chillerato. Boletín Oficial del Estado, A-2015-37, 211-213.

MORENO, C. (2006). Ingredientes mágicos y test clínicos en los anuncios como estrategias publicitarias. Comunicar, 27, 123-128.
PRAT À, MÁRQUEZ C, MARBÀ-TALLADA A (2008). Literacitat científica $i$ lectura. Temps d'Educació, 34, 67-82.

RAVITZ, J., HIXSON, N., ENGLISH, M., MERGENDOLLER, J. (2012). Using project based learning to teach 21st century skills: Findings from a statewide initiative. In American Educational Research Association Conference, Vancouver, Canada

RUIZ, N., DOMĖNECH-CASAL, J. (2016, en edició). Mission to stars: un proyecto de Ciencia y Tecnología alrededor de la astronomía, las misiones espaciales y la investigación científica. Aplicación y evaluación. Revista Eureka de Enseñanza y Divulgación de las Ciencias, en publicació.

SANMARTÍ, N. (2016, en edició). Trabajo por proyectos: ¿Filosofía o metodología? Cuadernos de Pedagogía (en publicació, novembre 2016).

SEGURA, M. (2010). Els elements en capsa. EduQ, 7, 23-30.

SIMARRO, C., COUSO, D., PINTÓ, R. (2013). Indagació basada en la modelització: un marc per al treball pràctic. Revista Ciències, 25, 35-43.

TRUJILLO, F. (2012). Propuestas para una escuela en el siglo XXI. La catarata, Fuencarral.

TRUJILLO, F. (2016, en edició). El diseño de proyectos y el currículo. Cuadernos de Pedagogía (en publicació, novembre 2016).

\section{NOTES}

[1] Grup de Treball EduWikiLab: https://eduwikilab.wordpress.com/

[2] Espai Wiki ABP del grup de Treball EduWikiLab: http://eduwikilababp.wikispaces.com/

[3] Web "Construïm el joc de l'Energia": https://sites.google.com/a/epiagranollers.cat/con struim-el-joc-de-l-energia/home

[4] Rúbriques i instruments d'avaluació de l'activitat "Construïm el joc de l'Energia":

https://sites.google.com/a/epiagranollers.cat/con struim-el-joc-de-l-energia/avaluacio-del-projecte 
[5] Sistema d'Avaluació Dialògica Integrada, Grup de Treball SEDI:

http://gruposedi.blogspot.com.es/

[6] Bastides per al treball per projectes:

http://cedec.ite.educacion.es/es/noticias-deportada/2061-15-documentos-imprescindibles

[7] Rúbrica per a l'elaboració i co-avaluació de pòsters científics:

https://sites.google.com/a/xtec.cat/c3/activitatsde-comunicacio-cientifica/posters-cientifics
[8] Pàgina web amb els materials didàctics del 1st Earth Fluids Scientific Congress:

https://sites.google.com/site/airwatercongress/.

[9] Xarxa de Competències Bàsiques:

http://xtec.gencat.cat/ca/curriculum/xarxacb/treb all-projectes/

[10] Xarxa d'Instituts Innovadors de l'ICE-UAB: http://blogs.uab.cat/icexarxaies/

[11] Instituts Projectant; https://institutsprojectant.wordpress.com/ 